\title{
GIS tools and programming languages for creating models of public and private transport potential accessibility in Szczecin, Poland
}

\section{Sławomir Goliszek ${ }^{1}[0$}

Received: 8 January 2020 / Accepted: 29 October 2020 / Published online: 26 February 2021

(c) The Author(s) 2021

\begin{abstract}
This article presents the results of public and private (car) transport accessibility modelling, which gives the room for the comparison of two types of transport throughout the whole day as well as the rush hours. Both public and private transport models are based on public available data, accessible via the Internet which is downloaded using a programming language and processed using the GIS tools. The public transport model is based on the GTFS data (General Transit Feed Specification), while the car model has been created from data on driving times derived from Google Maps ${ }^{\circledR}$ API. Both models presented in the article have been constructed for a specified period of time, namely from 5.00 am to $10.00 \mathrm{pm}$ in 15 -min intervals. The analysis of the above-mentioned models has allowed the comparison of differences in potential accessibility and its deviations at different times of the day. The disparities revealed by the study have indicated that there are certain times of the day when public transport is actually competitive with the private means of transport. The results of potential accessibility analysis are visualised with the use of maps, including the choropleth ones.
\end{abstract}

Keywords GTFS · Google maps API · GIS · Potential accessibility · Car model · Public transport model

JEL Classification $\mathrm{O} 18 \cdot \mathrm{R} 53 \cdot \mathrm{R} 42 \cdot \mathrm{L} 90 \cdot \mathrm{L} 86$

Sławomir Goliszek

sgoliszek@twarda.pan.pl

1 Institute of Geography and Spatial Organization, Polish Academy of Sciences, Warsaw, Poland 


\section{Introduction}

Potential accessibility is a significant scientific concept used in transport research. The potential accessibility method makes it possible to analyse entire regions, countries or cities in statistical and dynamic aspects, taking different infrastructural investments under consideration (Vickerman 1974). Since the very beginning, the potential accessibility theory has been based on spatial location of travel sources and destinations in the context of different means of transport, which relies mainly on the land use planning documents concerning areas and surrounding cities (Geurs and van Wee 2004; Hansen 1959; Harris 1954). A particular calculated value of potential accessibility indicates the potential of a given place or region, taking all relations with neighbouring areas into account. The times matrix, created while calculating potential accessibility, depends on the space resistance function which affects attractiveness of a given destination (Rosik et al. 2020). The research method used in this particular paper is the potential accessibility index, which is characterised by the fact that the longer the distance or travel time, the lower the attractiveness of the destination, e.g. population or GDP (Geurs and van Wee 2004). In most studies, potential accessibility is generally shaped by the potential of people living in a certain area. The population potential is a simple indicator depicting a situation in a particular place and time. People moves between different destinations using different means of transport in order to satisfy their everyday needs. Commuting to work (Merchant and Nemhauser 1978) and going shopping (Farber et al. 2016; Widener et al. 2015) are the two most frequently mentioned motives behind everyday travelling. Commuting to work is one of the major travel activities causing road congestion during the rush hours, while going shopping is also in the group of daily activities resulting in temporary road congestion (Goliszek et al. 2020). The two aforementioned activities (O'Kelly and Niedzielski 2009; O' Kelly et al. 2012) do not only cause the afternoon rush hours that makes people to use the public transport means. Recently, researchers are spending more and more time studying and describing operation of public and private transport during the morning (Goliszek 2017) and afternoon rush hours. Such analyses allow to formulate recommendations to avoid wasting time when travelling at different times of the day (Niedzielski and Boschmann 2014; Shearmur 2006; Shirgaokar 2014; Wang and Chen 2015; Yongling and Guonan 2009).

In recent years, the researchers have focused on public transport networks and their accessibility in the context of reaching various destinations when using modal transport. The General Transit Feed Specification (GTFS; Google 2018) data are most often used in such analyses (Hadas 2013; Rosik et al. 2021). They are made public by urban and regional transport operators and bodies responsible for urban transport systems management (Delling et al. 2014; Farber et al. 2014; Goliszek and Połom 2016; Karner 2018; Wessel and Widener 2016; Wessel et al. 2017; Widener et al. 2015, 2017). The GTFS data allow creating public transport models which generate accurate travel times according to time tables. This accuracy makes it possible to indicate time gaps in public transport operation 
schedules (Allen and Farber 2019). So far, the analyses using the GTFS data have been focused on commuting to shops and shopping centres (Farber et al. 2014; Widener et al. 2017), health centres (Neutens 2015), and cultural and educational facilities (Allen 2019) and they have indicated significant inequalities in accessibility to those services by means of public transport. While analysing the GTFS data, the researchers were pointing out some disadvantages and limitations of this data format. The analyses based on the GTFS data usually address the frequency of public transport services (El-Geneidy et al. 2015, 2016). Consequently, when the analysed time periods are relatively long, the modelling may not be accurate (Farber et al. 2016; Fransen et al. 2015; Wessel and Widener 2016; Wessel et al. 2017; Yin et al. 2020). However, the lower the frequency of transport services, the more important its precision of modelling.

Currently created models of individual transport are mainly based on data derived from online portals or systems gathering data on travel times from GPS transmitters in cars or mobile phones. The GPS data are processed by companies and then made public, e.g. they can be downloaded from Google Maps ${ }^{\circledR}$ website for free. As for other companies, some of them charge fees for making the data available. Google Maps ${ }^{\circledR}$ gathers and visualises real-time traffic data but it is also possible to check averaged travel time values (Lagrell et al. 2018; Wang and Xu 2011; Wang et al. 2013; Rothfeld et al. 2019). TomTom® and Google Maps®/ Transit are among the most well-known companies gathering and processing traffic data. However, if a regular user wants to download real-time data and create a model of a travel time matrix for several different destinations, it is not a simple procedure. In order to download data from Google Maps ${ }^{\circledR}$ API, a special application generating real-time map loads and saving them is required (GarcíaAlbertos et al. 2019; Xia et al. 2018). Such an application has to be written in a programming language. The author of this article has created an original model of the road transport system in the city of Szczecin using Google Maps ${ }^{\circledR}$ API data (Wang and $\mathrm{Xu}$ 2011) downloaded using an application written in Python 2.7.

Analysing data on public and private transport is a good research field, which has been developing dynamically in recent years. Moreover, the results of analyses based on open data sources are becoming more and more accurate. Taking different times of the day into account, such analyses would show when differences in operation of public and private transport are the smallest (Bach 1980; El-Geneidy and Levinson 2007; Salonen and Toivonen 2013; Shirgaokar 2014). In the study by Salonen and Toivonen (2013), three different types of models were implemented which includes simple, intermediate and advanced. It made it possible to assess the environmental and social impact of sustainable transport. Other studies that compare different types of transport focus on commuting to work and selection of the most suitable means of transport in the context of land use and planning (Bwire and Zengo 2020). A considerable advantage of the study presented herein is the fact that the advanced model used covers both private and public transport, just like in the study by Salonen and Toivonen (2013). More over, not only the peak hours are taken into consideration, but other hours of the day that are not obviously connected with everyday community are considered as well. 


\section{Research area, data and methods}

\subsection{Area and data}

The research area covers the city of Szczecin in its administrative boundaries, situated in north-western Poland. In 2018, the city had a population of approximately 400 thousand people (data published by the City Hall). The City Hall provides population data by the city districts. For the purpose of this study, the population data obtained from the City Hall have been used to estimate approximate number of citizens living in census areas. The city of Szczecin is divided into 1869 census areas, and the population for these areas is for 2011. In the article, the population in the estate was estimated at the census enumeration area according to the share of the population from 2011. The number of resident's from 2011 was updated using data from 2018. Therefore, the analysis presented in this article may be considered very detailed. For each census area a centroid has been designated, acting as a link between the areas. The census centroid is a spot with the highest population density. Locations of the centroids have been confirmed with the use of satellite images where location of housing estates is clearly visible (Fig. 1).

All the data necessary to calculate the potential accessibility for the public transport model sum up to as much as $70 \mathrm{~GB}$. The travel times matrixes for the $15-\mathrm{min}$ periods have been saved in DBF format, generated by ArcGIS. The matrix for an individual profile is $493 \mathrm{MB}$ and it consists of 3,493,161 records. For one type of transport, data gathered for only one day, in 15-min periods, sum up to 69 files. As the study covers two types of transport-138 files have been created for just one analysed day. All those files have been processed in R software (Vallone et al. 2020). The first task was to convert DBF files to the CSV format. Processing data in R allows reducing the file size and calculating the potential accessibility much faster. After the conversion, a $493 \mathrm{MB}$ matrix changed its size to approx. $70 \mathrm{MB}$. The program reduces the number of output files and calculates potential accessibility.

\subsection{Individual transport modelsparameters}

For the purposes of this article, the author has created an original model of private transport operation in Szczecin using Google Maps® API data, which had been downloaded with the help of a dedicated application written in Python 2.7. A basic grid of roads and footpaths has been created on the basis of the BDOT10k (https://www.codgik.gov.pl/), and it is presented in the upper left corner of Fig. 1. The BDOT10k base includes data on topographic objects with different attributes assigned to them, including road infrastructure. This database allowed to determine the most significant roads in the city and to create the model of private transport. The created road network depicts travel times between particular road sections (sections between the junctions) in 15 min intervals. Data on the travel times apply to selected weekdays - from Tuesday to Thursday and certain times of the day-from $5.00 \mathrm{am}$ to $10.00 \mathrm{pm}$. Limiting the study to the period between Tuesday and Thursday allows to exclude increased pre- and post-weekend traffic from the analysis. Mondays and 

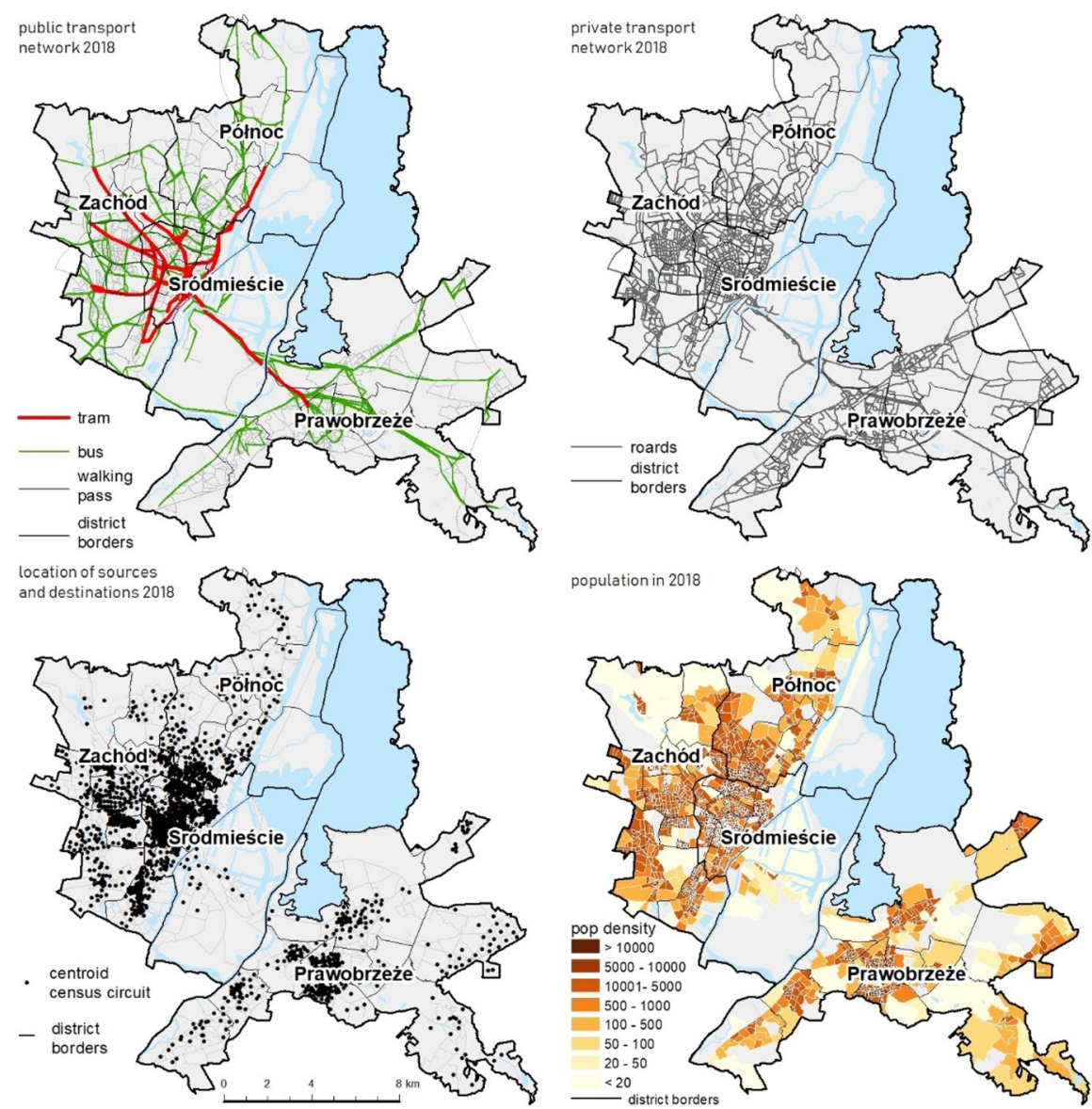

Fig. 1 Public transport (upper left map), road network (top map), centroids of census areas (left bottom map) and population numbers (lower map below)

Fridays have been intentionally excluded from the analysis as on those days, traffic may be heavier and caused by people returning from (Mondays) or going to (Friday) weekend trips. It may affect the pattern of everyday commuting. The application allows to generate map loads and download data on travel times between selected $X$ and $Y$ destinations. Google Maps ${ }^{\circledR}$ API data has been assigned to particular sections of the urban road network. The only restriction limiting the free-or-charge use of Google Maps ${ }^{\circledR}$ API is that it is possible to generate no more than 2500 map loads per day per API (Mercurio 2008; Schwartz 2010; Wang and Xu 2011; Rothfeldet al. 2019). It is possible to create individual transport (PrT) and public transport (PuT) models on the basis of data derived from Comprehensive Traffic Research in Szczecin. Such traffic research was done in Szczecin in 2010 and 2016. However, both models are limited, and in the case of the public transport model, the travel data do not accept timetable travel times under consideration. Additional disadvantage 
of these data is the fact that both models (for 2010 and 2016) were created only for the morning traffic, between 6:00 and 9:00 am, and for the afternoon traffic, between 3:00 and 6:00 pm. In 2016, CTR also covered investments planned to be implemented within the next few years (Comprehensive Traffic Research in Szczecin 2010; Comprehensive Traffic Research in Szczecin 2016).

The BDOT base contains approximately 15 thousand road sections covering the area of Szczecin. In the cause, the author excluded those sections which are not parts of the fast possible routes connecting the centroids during the first phase of the analysis. After deleting the unnecessary sections, the author merged those road sections which altogether created longer elements of the road network which allowed to reduce the number of Google Maps ${ }^{\circledR}$ API map loads to approximately 1,5 thousand (Fig. 1, upper right part of the map).

One-lane roads sections were the first ones selected for the analysis of travel times, and they are mostly one-way streets connecting the suburbs and the city centre. The bypass surrounding Szczecin which is partially running through the city has also been added to this category. Data on travel times between $5.00 \mathrm{am}$ and $10.00 \mathrm{pm}$ were directly downloaded by the application in the periods of 2-4 and 9-11 October 2018. The overall number of measurements for the selected one-way streets sections exceeded 10 thousand while the total length of the one-way sections is $159 \mathrm{~km}$. The graph in the upper left part of the map in Fig. 2 presents data on changes in the speed throughout the day.
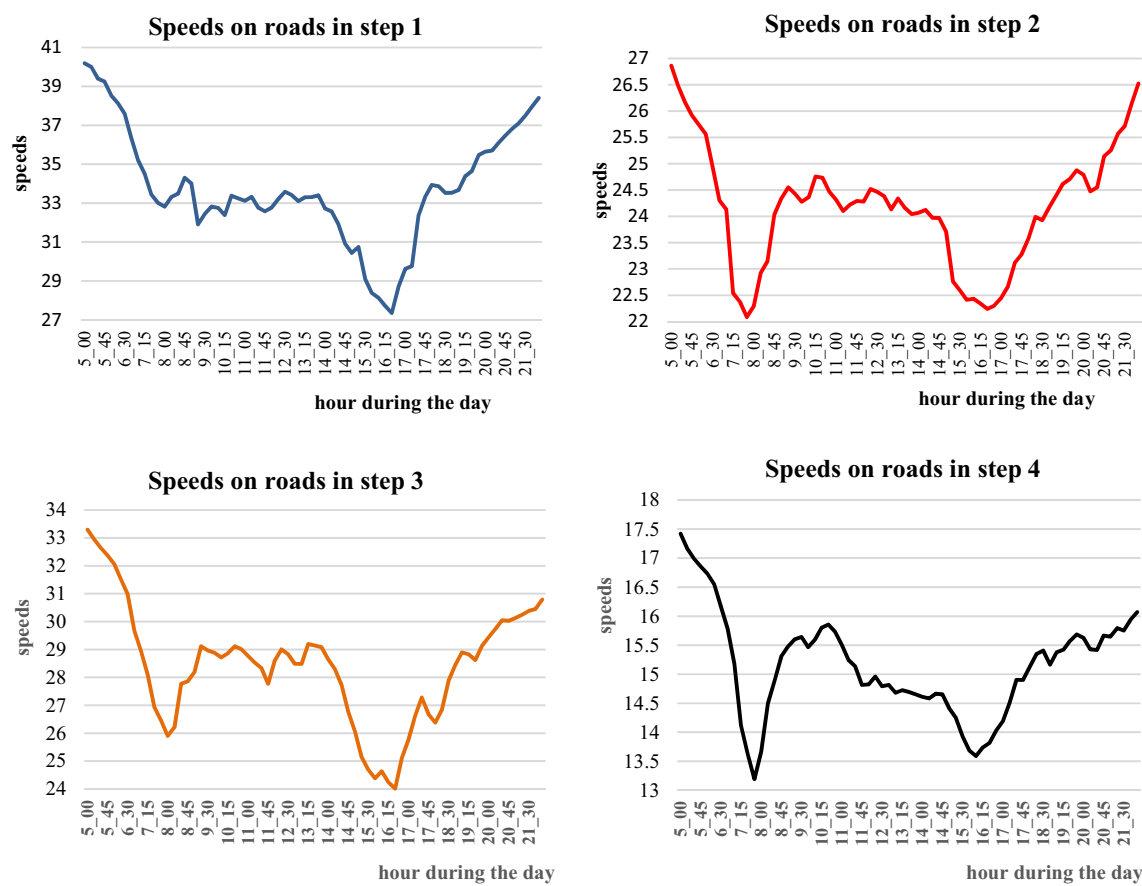

Fig. 2 Average speeds on the roads in Szczecin 
In the second phase of the analysis, sections of two-ways roads were taken under consideration, and in the case of this group, travel times have been averaged for both travelling directions. During the periods of 10-18 and 23-25 October 2018, approximately 20 thousand map loads were generated in order to download the necessary data. The total length of two-ways road sections is $146 \mathrm{~km}$ and the graph in the upper right part of the map in Fig. 2 presents the speed change for this type of road network.

The third phase of the analysis involved gathering data on travel times for local and internal roads. In this case, just as in phase 2 , the data were downloaded for both travelling directions and the averaged. They were downloaded during the period of 22-24 November and on 27 November 2018. The total length of local and internal road sections is $128 \mathrm{~km}$, and the graph in the bottom left part of the map in Fig. 2 presents the speed change for this type of road network.

During the last phase, data on travel times for the remaining road sections were gathered. This action was taken in order to complement the road network database and equally add sections which may significantly decrease travel times between the selected centroids. For each Sect. 5, measurements taken at different times of the day have been selected which allowed to indicate daily profiles. The values obtained during the fourth phase have been compared to the data on travel times which had been downloaded in the previous three phases of the analysis. This comparison allowed calculating travel times between 5.00 am and $10.00 \mathrm{pm}$ for those sections for which there had been no direct measurements done. The data were downloaded on 28 and 29 November 2018. The total length of sections analysed in the fourth phase is $371 \mathrm{~km}$. The speed change in the period between $5.00 \mathrm{am}$ and $10.00 \mathrm{pm}$ is presented in Fig. 2 (bottom right part of the map).

The total length of road network analysed in the context of individual transport is $804 \mathrm{~km}$. The selected sections for which travel times have been determined are presented in Fig. 3. The data on travel times were downloaded in October and November 2018. In order to construct the individual transport model over 60 thousand, map loads with $\mathrm{X}$ and $\mathrm{Y}$ coordinates were generated in real time between 5.00 am and $10.00 \mathrm{pm}$. The average speed for all analysed sections is $28,12 \mathrm{~km} / \mathrm{h}$. The average speed in 15-min time profiles for all analysed roads and streets in Szczecin is presented in Fig. 4. Assigning the data on travel times to the road network makes it possible to connect all destinations within the city and perform time calculations (Calabrese et al. 2011; Toole et al. 2015; Xia et al. 2018).

\subsection{Public transport model parameters}

Studies concerning transport accessibility in Szczecin with the use of the GIS (Geographic Information System) techniques have been carried out consecutively (Goliszek and Połom 2016; Goliszek 2017; Poelman and Dijkstra 2015; Stępniak and Goliszek 2017; Stępniak et al. 2019) and were based each time on open access GTFS data published by an official body managing public transport system in the city (GTFS open data Szczecin). In order to use the GTFS data for a particular city, it is necessary to install a certain plugin and some additional tools. It is necessary 


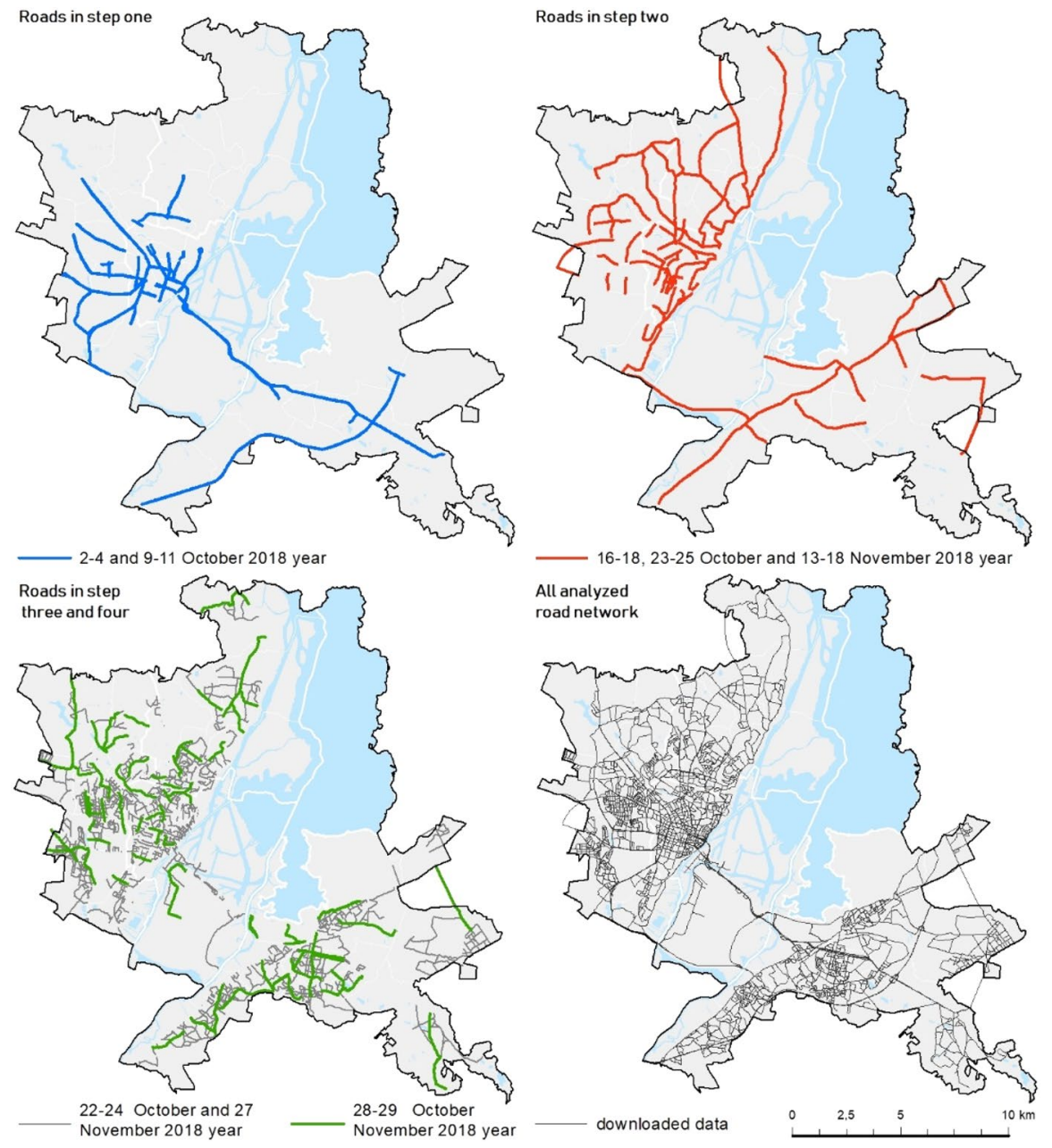

Fig. 3 Selected sections to measure travel time

to gain access to ArcGIS Network Analyst Tools. First, the GTFS data is used to generate stops and public transport routes, and thereafter, a network of pedestrian paths was added. Having all those layers, it is possible to generate a model of public transport for a particular city. For the purpose of this study, a map of public transport system in Szczecin has been created (Fig. 1, upper left corner). In order to construct the pedestrian transport model, which is required by the GTFS model, the road system network taken from the private transport model has been used. The average walking speed adopted for the study is $4,5 \mathrm{~km} / \mathrm{h}$, the same as in the analysis by Stępniak and Goliszek (2017). In the literature, there is no consent on the average walking speed which shall be adopted when analysing transport accessibility, e.g. Reyes et al. (2014) claim that the average walking speed for children is $3,2 \mathrm{~km} / \mathrm{h}$ while Fransen et al. (2015) and Ritsema et al. (2005) state that it is $4 \mathrm{~km} / \mathrm{h}$ and at 


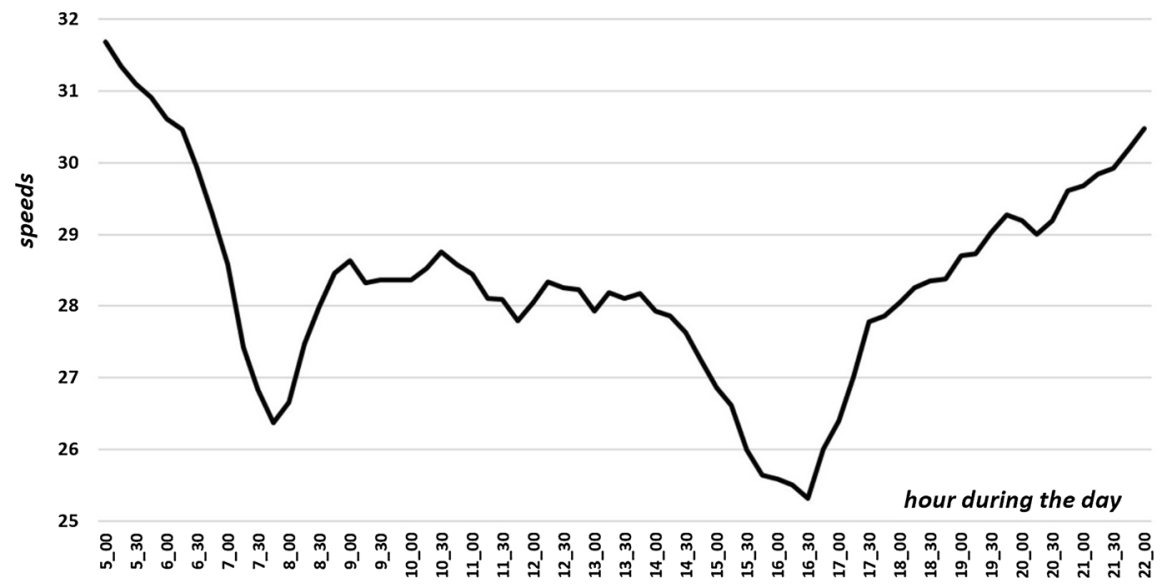

Fig. 4 Average speeds in Szczecin on roads weighted along the length of the section

the same time Fransen claim that it is also the average walking speed for the adults also and Ritsema et al. (2005) emphasise that this speed is concerned with linear motion. However, in the study by Shirgaokar (2014), the adopted average walking speed was 4,8 km/h. Meanwhile, Krizek et al. (2012) stated that people in the age between 14 and 64 years usually walk at the speed of $5,4 \mathrm{~km} / \mathrm{h}$. The average walking speed is a significant factor when assessing potential public transport accessibility as it is a part of travelling route. Public transport lines using GTFS data are generated between stops that are connected with each other by a bus or tram route. The built model based on pedestrian paths and the GTFS public transport network largely corresponds to the actual transit times of public transport.

\subsection{Research methods}

Potential accessibility is measured using the potential-gravity method. Harris (1954) and Hansen (1959) are believed to be the potential accessibility method precursors. However, it was Vickerman et al. (1999) who used first the potential accessibility indicator to evaluate transport infrastructure investments. The accessibility level of a given place is expressed by $A_{i}$. In this study, travel times between two census areas in Szczecin is expressed by $i$ and $j=t_{i}$. Selection of the means of transport (public or private) determines the travel time between $i$ and $j=t_{i j}$. This parameter was reduced by the spatial resistance function value $f\left(t_{i j}\right)$. The attractiveness of a given destination is expressed by all population POPsum. The formula for the potential accessibility is as follows:

$$
A_{i}(P O P s u m)_{i}=\Sigma_{j} P O P \operatorname{sum}_{j} \mathrm{f}\left(\mathrm{t}_{i j}\right)
$$


Coffey (1978) was the first one to use the potential accessibility method in regional studies. In the case of urban areas, the results are significantly affected by the function of spatial resistance (Allen and Farber 2020). In Szczecin, which is a medium-size city, the spatial resistance function includes shorter time distances. The most often used type of the spatial resistance function in potential accessibility studies is the exponential function: (Beriaet al. 2017)

$$
f\left(t_{i j}\right)=\exp \left(-\beta t_{i j}\right)
$$

where $\beta$ differentiates the level of destination attractiveness reduction. In order to determine time for the spatial resistance function, the author used data published in the study entitled "Comprehensive Traffic Research in Szczecin 2016" (CTR) where the average travel time for means of public transport in Szczecin was approximately $30 \mathrm{~min}$. In the case of travelling by car, the average travel time for Szczecin was approximately 26 min while in the case of public transport it was more than $30 \mathrm{~min}$. In the article, the value was rounded to $30 \mathrm{~min}$ - it is kind of a compromise between the average values obtained by CTR in 2016. Moreover, using the same values for both analysed types of transport makes it possible to compare them more effectively. The adopted value of the spatial resistance function parameter for the period of $30 \mathrm{~min}$ is -0.023105 , and it is sufficient to calculate both public and private transport potential accessibility. In this case, using more sharply falling function of spatial resistance will result in more densely populated areas being more visible on the map and the significance of the public transport system will be underestimated. Other researchers use the travel time median as a measure of passengers behaviour in order to calibrate the space resistance parameter for their models (Merlin 2020).

The final maps presenting differences between accessibility by the public (PuT) and private (PrT) transport were created using both models, according to the following formula:

$$
Q_{i}=\frac{A(P u T)_{i}}{A(P r T)_{i}}
$$

All the calculations in this article are based on the population data, which is the most commonly used parameter when calculating accessibility. The number of citizens usually depicts spatial distribution of most accessible services, and they are positively correlated with population density. It is also possible to use data on workplaces, yet this database is not free of charge.

\section{Results}

\subsection{Public and private transport potential accessibility}

The visible differences in the potential accessibility maps created for public and private transport systems in Szczecin results mainly from travel times included in the model. In the case of public transport, travel times are calculated using the 
door-to-door approach, explained and described by Salonen and Toivonen (2013). The door-to-door approach assumes that there are several time-consuming travel components that shall be taken under consideration when calculating total travel times. They are as follows: reaching a tram/bus stop, waiting for a tram/bus, changing (if necessary) and walking back according to the times used in the pedestrian model. As for the private transport model, there are also four components-reaching a car, driving time (calculated using Google Maps® API data), parking and walking to the final destination. The values that are added as the parking time equal the walking time between the centre of a particular census area and the nearest road/street. In fact, it is virtually impossible to measure parking time due its variability in different cities in Poland. Actually, it may be random values. The only places where the parking time may be assessed are some newly built buildings with monitored parking areas. However, a correlation was demonstrated between the peak hours and possibility to park in city centres (Assemi et al. 2020). Outside the city centre, the abovementioned values are obviously higher as the distance between the centroids and the roads is longer. Moreover, the centroids located in the city centre are smaller. The parking time that usually takes from 1 to 4 min does not significantly affect the total travel time by car. Total travel time, after summing up all the components, is always shorter in the case of private transport. The potential accessibility, while using the same values in the map legend, is presented in Figs. 5 and 6.

Travel times for public and individual transport may be similar provided that public transport services are of high frequency and that the public transport means do not use the road system to avoid congestion. In Szczecin, the only places where it is possible are situated near the tram network. The suburbs are visible in the potential accessibility maps for both private and public transport, and the core is always characterised by higher accessibility values, which results from the specificity of the potential-gravity method. Taking the selected times of the day $(5.00 \mathrm{am}, 8.00 \mathrm{am}$, $12.00 \mathrm{pm}, 5.00 \mathrm{pm}$ and $10.00 \mathrm{pm}$ ) under consideration, it is clear that in the case of public transport, the potential accessibility level is stable or it slightly increases throughout the day (Fig. 6). There is also a visibly higher accessibility during the rush hours. The higher frequency, the shorter waiting and changing times. When analysing the same times of the day for private transport, it becomes clear that, except the rush hours, the accessibility for both the peripheral areas and the city centre is higher than during the morning and afternoon rush hours (Figs. 7 and 8). The values of potential accessibility are negatively affected by the road congestion. Decreasing travel speed and increasing travel times are presented in Fig. 4.

\subsection{Comparison of the public and private transport accessibility}

It becomes clear comparing calculated values of accessibility for public and private means of transport in Szczecin when the values for private transport are almost two times higher. The disparities in the potential accessibility are even higher when taking the suburbs under consideration. Consequently, the private transport has significantly higher values of the potential accessibility. The highest disparities were recorded in Prawobrzeże district. Here, it is worth mentioning that in the case of 

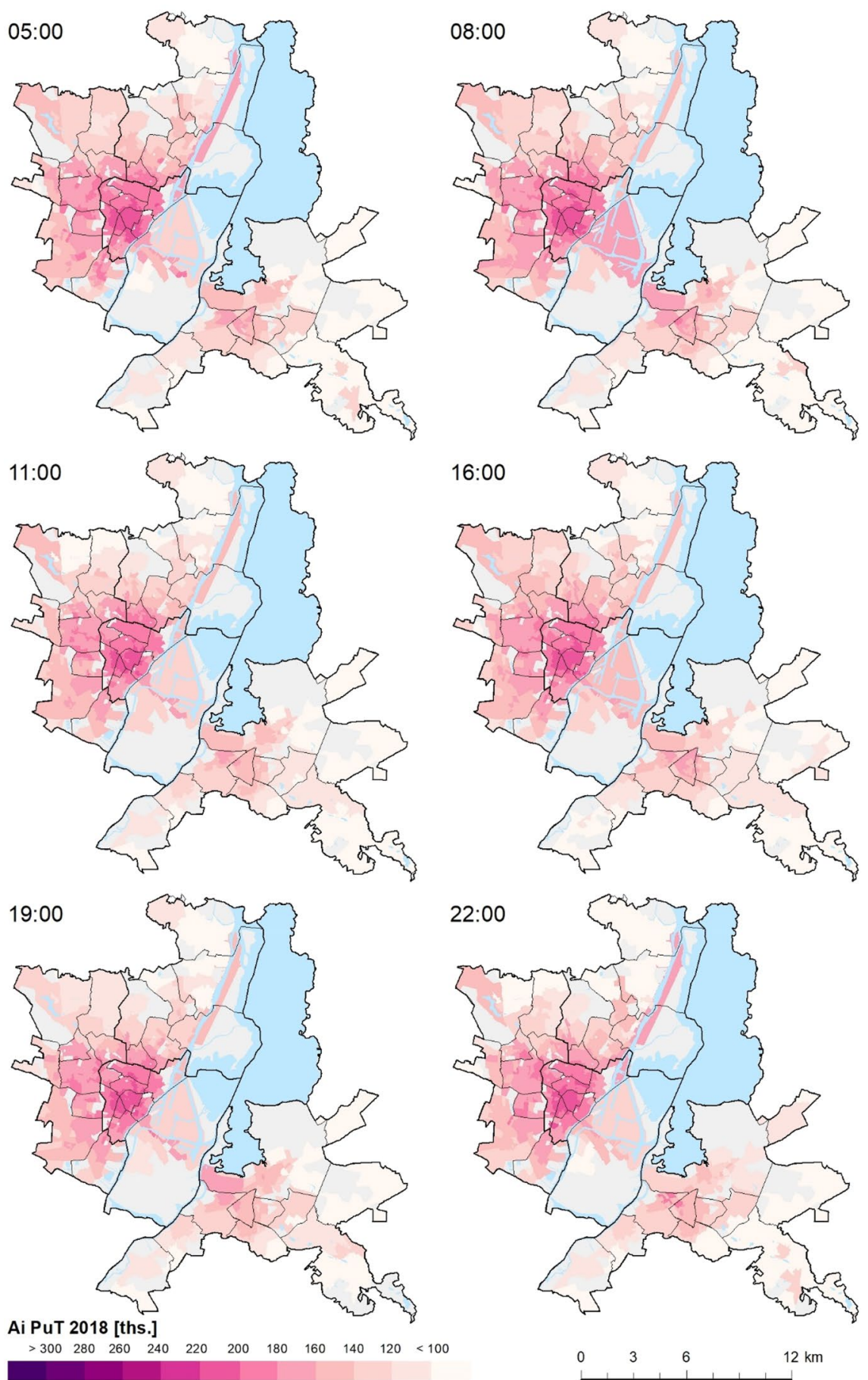

Fig. 5 Distribution of potential accessibility by public transport 

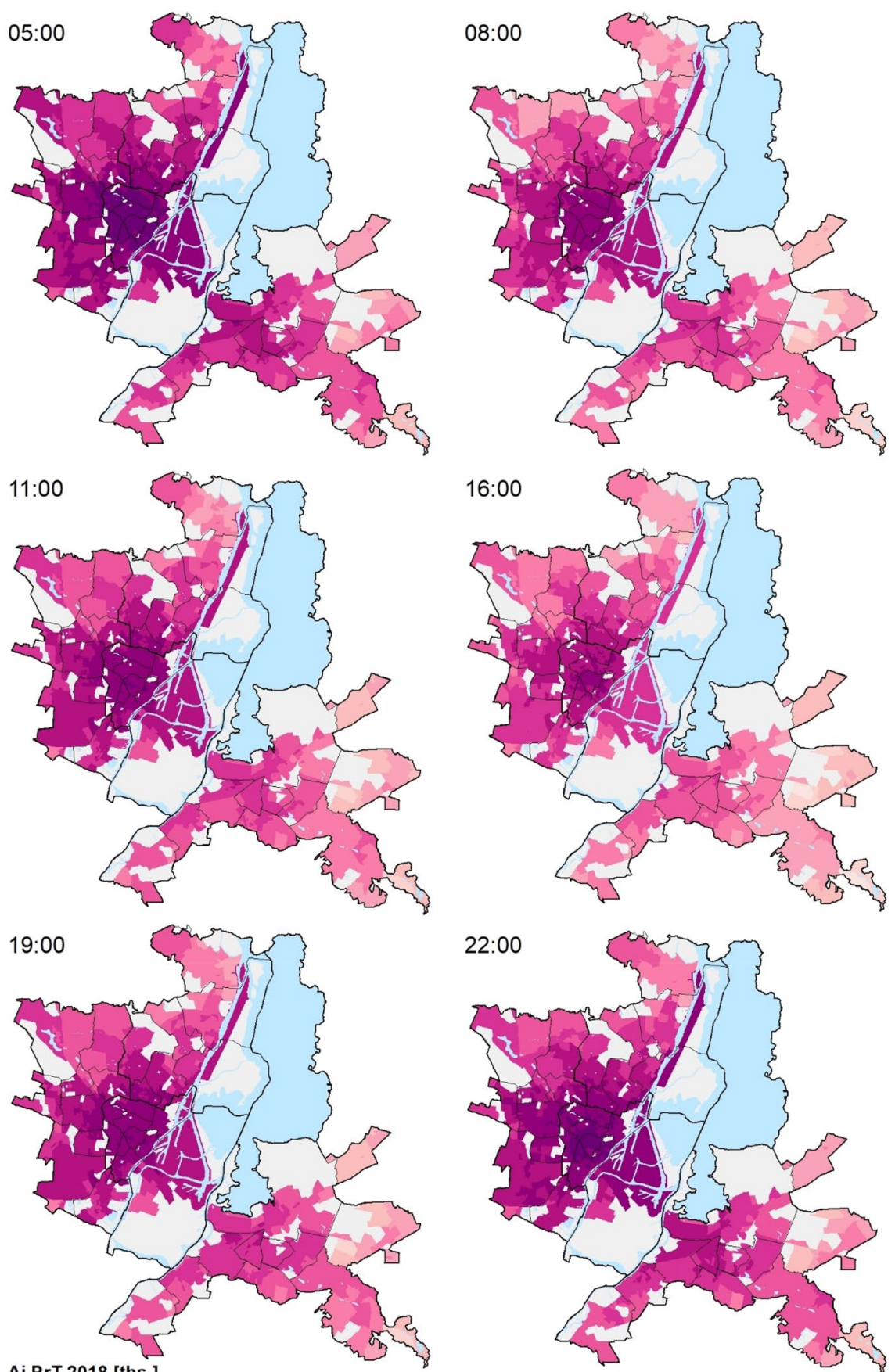

Ai PrT 2018 [ths.]

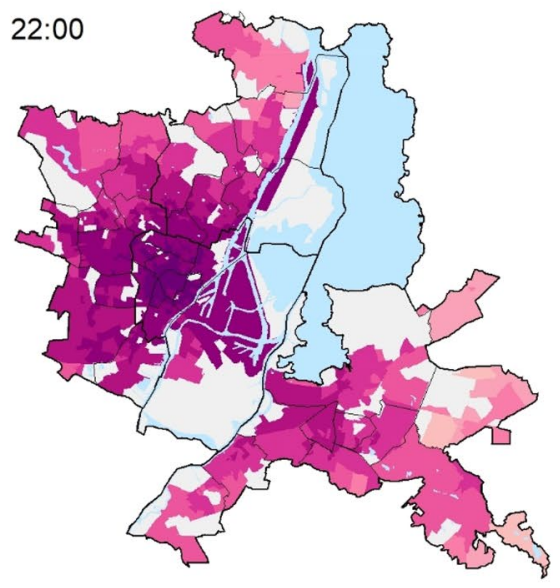

$\begin{array}{lllllllllll}300 & 280 & 260 & 240 & 220 & 200 & 180 & 160 & 140 & 120 & <100\end{array}$

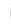

3

6

$12 \mathrm{~km}$

Fig. 6 Distribution of potential accessibility by private transport 


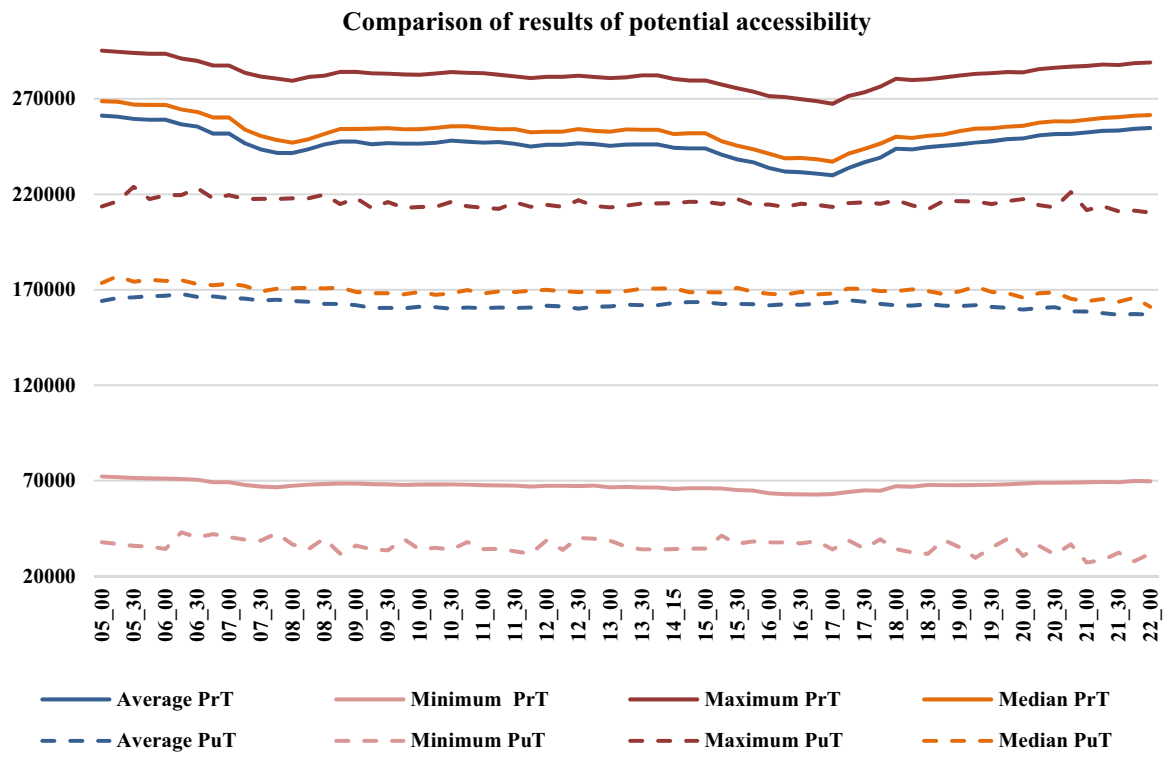

Fig. 7 Comparison of results of potential accessibility by public and private transport

suburbs, the time of leaving homes as well as public transport routes are two often factors largely affecting public transport services. In Szczecin, most public transport routes are typically found running radially to the city centre and there are only few lines running across the districts. As a result, the potential accessibility of public transport is much lower there. In Szczecin, public transport services are competitive with the means of private transport only in the city centre and only in areas served by the tram system. In the city centre, minor disparities between the two analysed types of transport are observed in the rush hours. Off peak, the public transport potential accessibility is almost two times lower, even in places located near the tram stops. In peripheral areas at non-peak hours, the individual transport potential accessibility is nearly three times higher, in extreme cases even five times, than the values of potential accessibility calculated for the means of public transport. The smallest accessibility disparities are during the morning and afternoon rush hours in the city centre, Śródmieście district, and in the central part of Prawobrzeże district. In Prawobrzeże, it is a result of situating a tram terminus on the outskirts of Słoneczne housing estate. The terminus was constructed in 2015 under the first phase of the fast tram project. The above-mentioned minor differences in accessibility result mainly from the existence of three tram lines running from Prawobrzeże to Śródmieście and terminating in the southern part of Północ district and in the southern and northern parts of Zachód district. Thanks to the fast trains in Prawobrzeże that has enhanced the public transport accessibility in the rush hours which is almost as high as the accessibility calculated for the means of private transport (Fig. 8). 

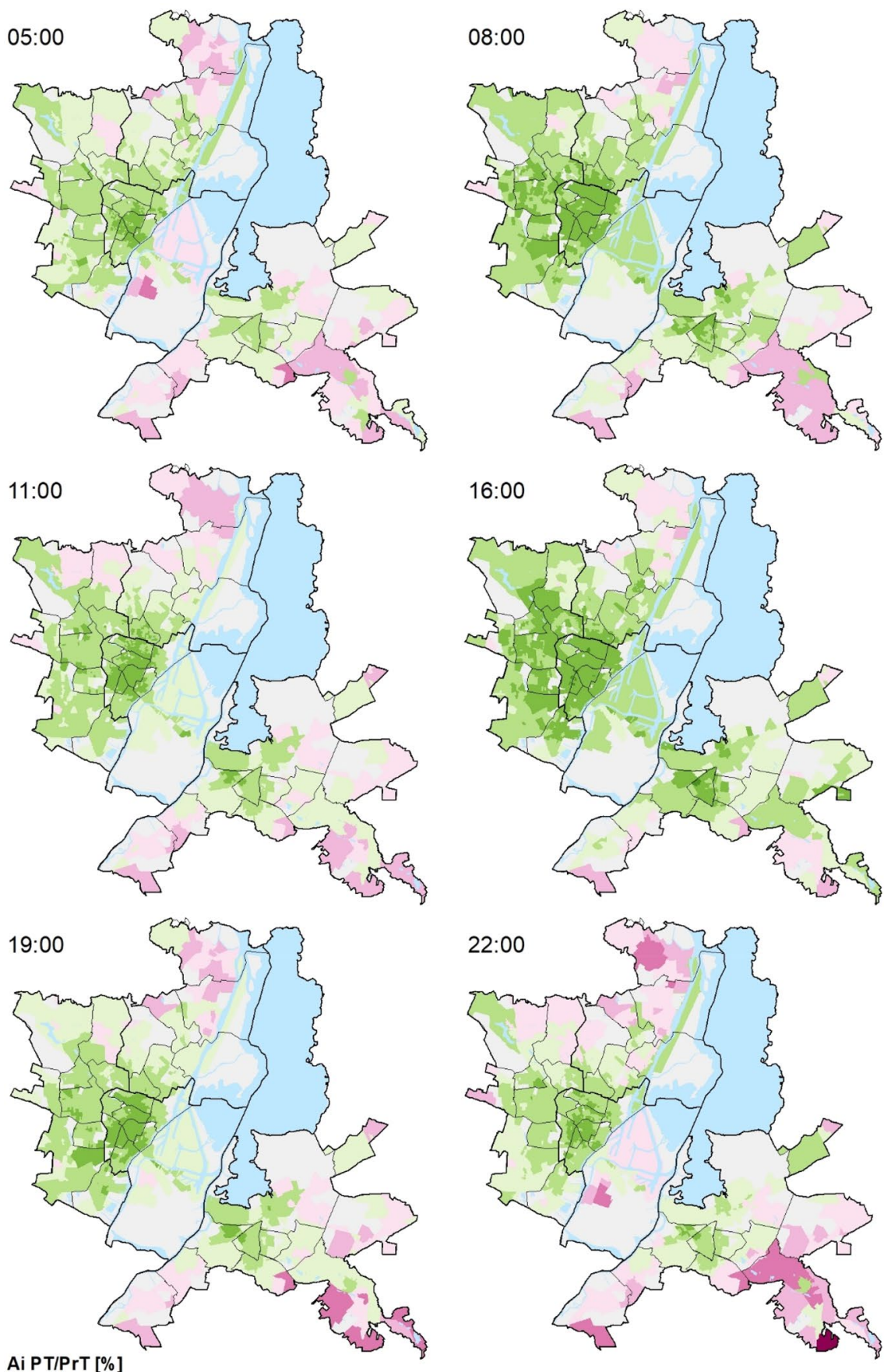

$\begin{array}{lllllllll}>90 & 80 & 70 & 60 & 50 & 40 & 30 & 20 & 10<\end{array}$

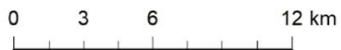

Fig. 8 Percentage of potential accessibility by public transport in relation to individual transport 


\subsection{Diversification of the potential accessibility at different times of the day}

The disparities in the calculated values of potential accessibility provide information on the places where the citizens are exposed to drop in the transport accessibility throughout the day and between the planned departures of the means of public transport. As for the public transport, the highest drops are observed in the northern part of Północ district and in the eastern part of Prawobrzeże district. The lowest disparities in public transport potential accessibility are in the central parts of Śródmieście and Prawobrzeże districts-both areas are covered by the tram network (Wessel and Widener 2016; Wessel et al. 2017; Widener et al. 2017). Special attention should be given to the areas in Prawobrzeże, as the minor disparities observed there are the result of organisational changes as well as the fact that the fast tram terminus is located there also. The organisational changes included launching some new lines running to the terminus and connecting some new areas within the district with destinations located on the left bank of the river (Fig. 9). The visible drops in Fig. 9 depict daily deviations to the minimum and maximum potential accessibility observed between 5.00 a.m. and 10.00 p.m.

The daily disparities in the potential accessibility calculated for the means of private transport are much smaller than in the case of the public transport. The results are almost entirely affected by the road congestion. The highest disparities (30\%) are observed in the northern part Zachód district and in the eastern part of Prawobrzeże district. Smaller disparities in the calculated private transport potential accessibility values are observed in the southern part of Zachód district and in the south-western Prawobrzeże. Those inequalities would have been definitely larger if it had not been for a bridge on national road 31 connecting the two districts. As for the public transport, the disparities are visibly higher as there is only one bus running across the
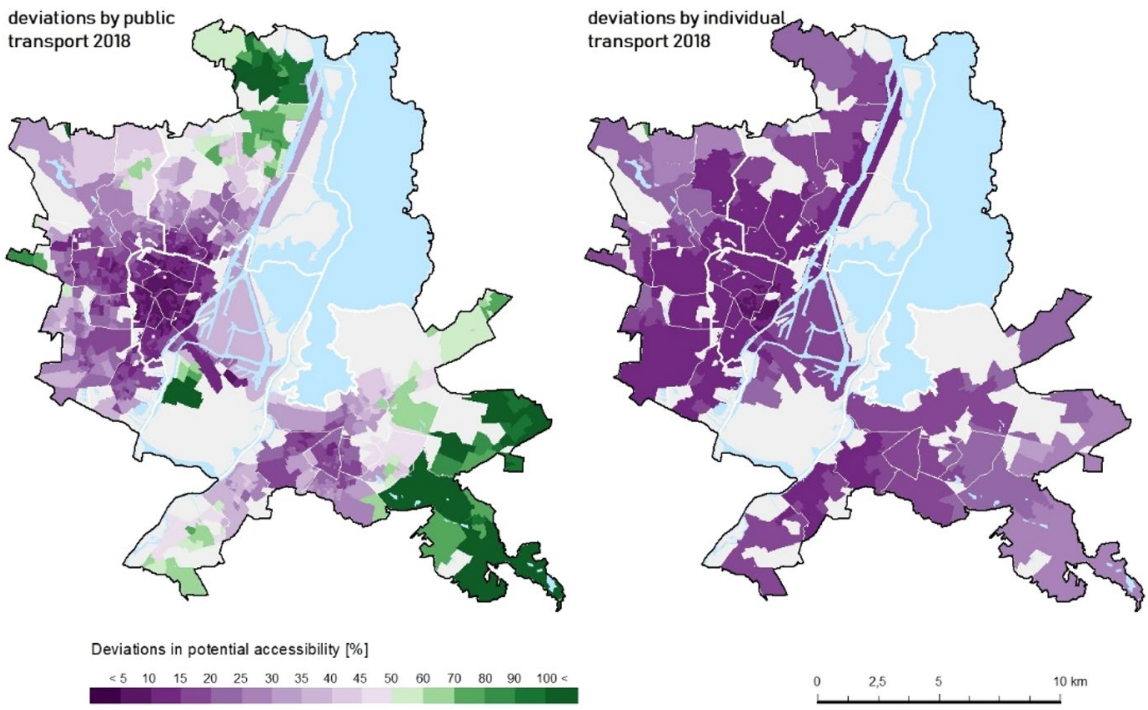

Fig. 9 Diversification of the potential accessibility by individual and public transport during the day 
bridge with a relatively low 20 -min frequency. The bridge on national road 31 is the one across which the traffic moves on smooth even during the rush hours. The situation is different in the case of the second bridge on road 10 and regional road 115 where the high peak hour congestion is observed.

\section{Discussion}

Recently, advances GIS original methods and techniques as well as open data sources allow to create transport models which can be very useful for scientific research (Frei et al. 2017; Xia et al. 2018). All the tools, including GIS, R and Python, share one basic advantage which is simple and easily accessible. Selecting an appropriate original method for both calculating and visualising results of the potential accessibility analysis is extremely important when evaluating and comparing private and public transport systems. This article proves that a model based on the GTFS and Google Maps® API data may be useful to perform such comparative studies (Rothfeld et al. 2019). However, implementing simple models based on average speed values always involves the possibility of errors and misinterpretation. Larger disparities between real GTFS travel times and data obtained from Google Maps ${ }^{\circledR}$ API are observed in cities with larger population density. Additionally, models based on the GTFS data do not capture road congestion, nonetheless, delays are taken into account when constructing public transport timetables making the model a bit more accurate. The study presented in this article is based on almost 60 thousand Google Maps® API map loads. The author states that both created models can be compared and an average error for travel time deviation values for the means of private and public transport is not large. However, it is worth mentioning that those models do not capture unpredictable events, e.g. car crashes or inoperability of vehicles, which may largely affect traffic or even make it impossible.

The author of this study has decided to compare public and private transport accessibility in 15-min intervals between $5.00 \mathrm{am}$ and $10.00 \mathrm{pm}$. The selected times of the day cover the entire period of public transport daily operation. During the selected periods of time, including the morning and afternoon rush hours, it is clearly visible that the individual transport accessibility is decreasing ( $\mathrm{Li}$ et al. 2019). Using the 15-min intervals has significantly differentiated the results obtained. Large disparities for the means of public transport may result from the fact that data based on the timetables have been used and it is possible that implementing random home-leaving hours will be a better solution (Stępniak et al. 2019). However, the main objective of this study was to identify inter-linkages in public transport operation only in the period between 5.00 am and $10.00 \mathrm{pm}$. Stępniak and Goliszek (2017) used a completely different approach, implementing 15-min intervals but analysing the whole 24 -h period. Obviously, their results indicated a drastic drop in accessibility between $10.00 \mathrm{pm}$ and $5.00 \mathrm{am}$. In other accessibility studies, some shorter intervals were used, e.g. Jarv et al. (2018) used 12-min ones justifying that they are appropriate to analyse public transport systems. Fayyaz et al (2017) used 10-min periods but in this study, the period of 
time between 4.00 am and 10.00 pm was analysed. When comparing public and private transport travel times, some authors did not use Google Maps ${ }^{\circledR}$ API. They used data provided by the study on road traffic instead and on that basis they assessed individual transport travel times (Owen and Levinson 2015). In Australia, individual and public transport models were created with the use of surveys. The surveys also showed that pupils may change the type of transport if it is not twice as slow (Mehbub Anwar and Yang 2017).

In addition, using 15-min intervals may affect the results for public transport while its impact is negligible in private means of transport. In the case of the private transport model, the source of data is the most important factor. The TomTom ${ }^{\circledR}$ data are perceived the most plausible, yet they are not open access data. The Google Maps ${ }^{\circledR}$ API data are free of charge, and they can be considered plausible enough. After its verification, the model based on the Google Maps® API data is good for determining travel times (Wang and $\mathrm{Xu}$ 2011). When comparing means of public and private transport, the final chosen model of transport is significant as it affects the traffic and congestion. More and more authors are paying attention to changes in transport policies resulting from increased road congestion (Arellana et al. 2012). In some cases, transport policies assume implementing special fees for entering the city centre (Ramosa et al. 2017). Wang et al. (2013) pointed out that people commuting by private cars pay more attention to comfort, travel time and reliability of the vehicle while the people travelling by the means of public transport cost-effectiveness and the opportunity to relax while travelling are more important.

A simple population potential accessibility indicator was used in this study. It is a frequently used research method for measuring potential accessibility but there are still other methods. Numerous studies were based on variability of accessibility (Merchant and Nemhauser 1978) and effectiveness of commuting (Niedzielski et al. 2020) to workplaces or selected services (Farber et al. 2016; Widener et al. 2015). Workplaces are often located outside the most densely populated areas. Usually, when it comes to services, they are located in the city centres and they are not evenly distributed. Subjecting only the selected travel destinations in the study is an obvious limitation, yet the author states that using the population potential accessibility indicator significantly reduces the research gap.

\section{Conclusions}

In order to draw any plausible conclusions, it is vital to use comparable data while modelling public and private transport accessibility. It is also advisable to use the door-to-door approach, just like Salonenn and Toivonen (2013) and the author of this article did. The door-to-door analysis gives room to compare net travel time using different research original methods. The net travel time parameter calculated for both analysed times of transport reduces the risk of data misinterpretation. It is worthy to emphasise that the calculated travel times may significantly differ from the ones generated on the basis of time tables. Reliability of public transport also contributes to this. However, the most reliable means of transport is the underground as it operates outside the road network. The trams do 
not use the road network but there are some road sections with the tram tracks. The least reliable means of transport is the bus as it uses the road system and does not often operate according to the time table. Consequently, the calculated results for this means of transport are vitiated by the largest error. The data used in transport models should be publicly available and free for downloading. Accessibility of transport data has significantly increased as they have started to be published by institutions responsible for urban transport management, thanks to the GTFS format. The more transit data are publicly available, the more studies on public transport are published (Bok and Kwon 2016; Calabrese et al. 2011). This increased open data accessibility is mainly a result of the INSPIRE directive implementation, thanks to the large amounts of data that have been made publicly available. Although the INSPIRE directive does not cover the GTFS data, most of the files in this format are published and gathered in open repositories (INSPIRE 2018).

As for private transport, the situation is much worse. And in most cases, the data are too expensive and as such a regular researcher cannot afford it. TomTom ${ }^{\circledR}$ or Google Maps ${ }^{\circledR}$ are examples of companies gathering and processing time travel data for individual transport. In order to get TomTom® data, you have to pay for it. Google Maps® does not make its data available entirely for free, yet when having an application; one can generate 2500 map loads free of charge. However, not only the issue of data availability is important, another key factor is data volume, especially in the context of the gravity and potential analysis. In 2018, when the number of loads exceeded 2500, it was necessary to pay a fee. The fee was not fixed and it depended on the number of loads. Creating a model of private transport for a city having a population larger than 500 ths. people using the Google Maps API is both time-consuming and costly. In such a case, it is better to simply buy data from TomTom and save the time needed to create a model. The author of this study has created an original model of individual transport based on open data downloaded from Google Maps ${ }^{\circledR}$ API. Thanks to such an approach that made it possible to perform detailed analyses of potential accessibility in census areas in Szczecin. The model has been created with the use GIS techniques and an application written in Python 2.7. This original method has allowed comparing public and the private transport systems. However, this model has one fundamental disadvantage - it has been created for one particular city and for one particular period of time for which the data was downloaded.

According to Rothfeld et al. (2019), each and every study based on data downloaded from Google Maps API shows that private cars are always faster than the public transport means. Using open data sources, like Google Maps API is very convenient and allows to create models for selected periods of time in a certain day of the week (Freiet al. 2017; García-Albertoset al. 2019; Xia et al. 2018).

Figure 8 shows places with potential accessibility by the means of public transport are comparable to the accessibility by private car. Those places are mainly located in the city centre and in the central part of Prawobrzeże. During the morning and afternoon peak hours, their potential accessibility by public transport reaches $80 \%$ of the potential accessibility by private transport. Such analyses may be useful 
when planning spatial development of urban areas, especially when implementing new infrastructural projects that may affect traffic congestion in the whole city.

Acknowledgements The author gratefully acknowledges the support of the Polish National Science Centre allocated on the basis of the decision no. UMO-2017/25/N/HS4/01237 and UMO-2020/36/T/ HS4/00131. I would like to thank my friend Łukasz D. which wrote python application for me. Because the application is intellectual property of Łukasz D. will not be published in this article.

Open Access This article is licensed under a Creative Commons Attribution 4.0 International License, which permits use, sharing, adaptation, distribution and reproduction in any medium or format, as long as you give appropriate credit to the original author(s) and the source, provide a link to the Creative Commons licence, and indicate if changes were made. The images or other third party material in this article are included in the article's Creative Commons licence, unless indicated otherwise in a credit line to the material. If material is not included in the article's Creative Commons licence and your intended use is not permitted by statutory regulation or exceeds the permitted use, you will need to obtain permission directly from the copyright holder. To view a copy of this licence, visit http://creativecommons.org/licen ses/by/4.0/.

\section{References}

Allen J (2019) Mapping differences in access to public libraries by travel mode and time of day. Lib Inf Sci Res 41:11-18. https://doi.org/10.1016/j.lisr.2019.02.001

Allen J, Farber S (2019) Sizing up transport poverty: a national scale accounting of low-income households suffering from inaccessibility in Canada, and what to do about it. Trans Policy 74:214-223. https://doi.org/10.1016/j.tranpol.2018.11.018

Allen J, Farber S (2020) A measure of competitive access to destinations for comparing across multiple study regions. Geographical Analysis 52:69-86. https://doi.org/10.1111/gean.12188

Arellana J, Daly A, Hess S, de Dios OJ, Rizzi LI (2012) Development of surveys for study of departure time choice: two-stage approach to efficient design. Transp Res Record: J Trans Res Board 2303:1. https://doi.org/10.3141/2303-02

Assemi B, Baker D, Paz A (2020) Searching for on-street parking: an empirical investigation of the factors influencing cruise time. Trans Policy 97:186-196. https://doi.org/10.1016/j.tranp ol.2020.07.020

Bach L (1980) Locational models for systems of private and public facilities based on concepts of accessibility and access opportunity. Envir Plann A 12:301-320. https://doi.org/10.1068/a1203 01

Beria P, Debernardi A, Ferrara E (2017) Measuring the long-distance accessibility of Italian cities. J Transp Geogr 62:66-79. https://doi.org/10.1016/j.jtrangeo.2017.05.006

Bok J, Kwon Y (2016) Comparable measures of accessibility to public transport using the general transit feed specification. Sustainability 8(3):224. https://doi.org/10.3390/su8030224

Bwire H, Zengo E (2020) Comparison of efficiency between public and private transport modes using excess commuting: An experience in Dar es Salaam. J Transp Geogr 82(2020):102616. https://doi. org/10.1016/j.jtrangeo.2019.102616

Calabrese F, Di Lorenzo G, Liu L, Ratti C (2011) Estimating Origin-Destination fows using opportunistically collected mobile phone location data from one million users in Boston Metropolitan Area. IEEE Pervasive Comput 10(4):36-44

Coffey W (1978) Income Relationships in boston and toronto: A tale for two countries? Canadian Geogr 2(22):112-129. https://doi.org/10.1111/j.1541-0064.1978.tb00626.x

Comprehensive Traffic Research in Szczecin 2010, https://bip.um.szczecin.pl, access 17.11.2018

Comprehensive Traffic Research in Szczecin 2016, https://bip.um.szczecin.pl, access 19.11.2018

Delling D, Pajor T, Werneck RF (2014) Round-based public transit routing. Trans Sci 49(3):591-604. https://doi.org/10.1287/trsc.2014.0534

El-Geneidy A, Buliung R, Diab E, van Lierop D, Langlois M, Legrain A, Van L, Langlois M, Legrain A (2015) Non-stop equity: assessing daily intersections be-tween transit accessibility and social 
disparity across the greater toronto and hamilton area (GTHA). Environ Plann B 43:540-560. https ://doi.org/10.1177/0265813515617659

El-Geneidy A, Levinson D (2007) Mapping accessibility over time. J Maps 3(1):76-87. https://doi. org/10.1080/jom.2007.9710829

El-Geneidy A, Levinson D, Diab E (2016) The cost of equity: Assessing transit accessibility and social disparity using total travel cost. In: 95th Annual Meeting of the Transp Res Board Washington D.C. USA, 1-34.

Farber S, Benjamin R, Liwei F (2016) Space-time mismatch between transit service and observed travel patterns in the Wasatch Front, Utah: a social equity perspective. Travel Beh Soc 4:40-48. https:// doi.org/10.1016/j.tbs.2016.01.001

Farber S, Morang MZ, Widener MJ (2014) Temporal variability in transit-based ac-cessibility to supermarkets. Appl Geogr 53:149-159. https://doi.org/10.1016/j.apgeog.2014.06.012

Fayyaz S, Liu XC, Zhang G (2017) An efficient General Transit Feed Specification (GTFS) enabled algorithm for dynamic transit accessibility analysis. PLoS ONE. https://doi.org/10.1371/journ al.pone. 0185333

Fransen K, Neutens T, Farber S, De Maeyer P, Deruyter G, Witlox F (2015) Identifying public transport gaps using time-dependent accessibility levels. J Transp Geogr 48:176-187. https://doi. org/10.1016/j.jtrangeo.2015.09.008

Frei C, Hyland M, Mahmassani HS (2017) Flexing service schedules: assessing the potential for demandadaptive hybrid transit via a stated preference approach. Transp Res Part C Emerg Technol 76:7189. https://doi.org/10.1016/j.trc.2016.12.017

García-Albertos P, Picornell M, Salas-Olmedo MH, Gutiérrez J (2019) Exploring the potential of mobile phone records and online route planners for dynamic accessibility analysis. Transp Res Part A Policy Pract 125:294-307. https://doi.org/10.1016/j.tra.2018.02.008

Geurs KT, van Wee B (2004) Accessibility evaluation of land-use and transport strategies: review and research directions. J Transp Geogr 12:127-140. https://doi.org/10.1016/j.jtrangeo.2003.10.005

Goliszek S (2017) Space-time variation of accessibility to jobs by public transport-a case study of Szczecin. Europa XXI 33:49-66

Goliszek S, Połom M (2016) The use of general transit feed specification (GTFS) application to identify deviations in the operation of public transport at morning rush hour on the example of Szczecin. Europa XXI 31:51-60

Goliszek S, Połom M, Duma P (2020) Potential and cumulative accessibility of workplaces by public transport in Szczecin. Bull Geogr Socio-economic Ser 50:133-146. https://doi.org/10.2478/ bog-2020-0037

Google (2018) General transit feed specification reference. https://developers.google.com/transit/gtfs/ reference. Accessed November 2018

Hadas Y (2013) Assessing public transport systems connectivity based on Google Transit data. J Transp Geogr 33:105-116. https://doi.org/10.1016/j.jtrangeo.2013.09.015

Hansen WG (1959) How accessibility shapes land use. J Am Inst Plann 25:73-76. https://doi. org/10.1080/0-1944365908978307

Harris CD (1954) The market as a factor in the localization of industry in the United States. Ann Am Assoc Geogr 44:315-348. https://doi.org/10.1080/00045605409352140

INSPIRE (2018, December 15) Available online: https://inspir-e.jrc.ec.europa.eu/ (12.10.2018).

Järv O, Tenkanen H, Salonen M, Ahas R, Toivonen T (2018) Dynamic cities: loca-tion-based accessibility modelling as a function of time. Appl Geogr 95:101-110. https://doi.org/10.1016/j.apgeo g.2018.04.009

Karner A (2018) Assessing public transit service equity using route-level accessibility measures and public data. J Transp Geogr 67:24-32. https://doi.org/10.1016/j.jtrangeo.2018.01.005

Krizek KJ, Horning J, El-Geneidy A (2012) Perceptions of accessibility to neighbourhood retailand other public services. In: Geurs KT, Krizek KJ, Reggiani A (eds) Accessibility analysis and transport planning challenges for Europe and North America. Edward Elgar Cheltenham, Cheltenham, pp 96-117

Lagrell E, Thulin E, Vilhelmson B (2018) Accessibility strategies beyond the private car: a study of voluntarily carless families with young children in Gothenburg. J Transp Geogr 72:218-227. https:// doi.org/10.1016/j.jtrangeo.2018.09.002

Li H, He F, Lin X, Wang Y, Li M (2019) Travel time reliability measure based on predictability using the Lempel-Ziv algorithm. Transp Res Part C: Emerg Tech 101:161-180. https://doi.org/10.1016/j. trc.2019.02.014 
Mehbub Anwar AHM, Yang J (2017) Examining the effects of transport policy on modal shift from private car to public bus. Proc Eng 180:1413-1422. https://doi.org/10.1016/j.proeng.2017.04.304

Merchant D K, Nemhauser G L (1978) A model and an algorithm for the dynamic traffic assignment problems. Transp Sci 12(3)183-199. https://www.jstor.org/stable/25767912

Mercurio R (2008) Improving operation, marketing and customer service with Google maps. Malaya business insight. Available from: https://www.malaya.com.ph/ june08/info1.html Accessed 8 December 2018

Merlin LS (2020) A new method using medians to calibrate single-parameter spatial interaction models. J Transp Land Use 13(1):49-70. https://doi.org/10.5198/jtlu.2020.1614

Neutens T (2015) Accessibility, equity and health care: review and research directions for transport geographers. J Transp Geogr 43:14-27. https://doi.org/10.1016/j.jtrangeo.2014.12.006

Niedzielski MA, Boschmann EE (2014) Travel time and distance as relative accessibility in the journey to work. Ann Am Assoc Geogr 104(6):1156-1182. https://doi.org/10.1080/00045608.2014.958398

Niedzielski MA, Hu Y, Stępniak M (2020) Temporal dynamics of the impact of land use on modal disparity in commuting efficiency. Comp Environ Urban Syst. https://doi.org/10.1016/j.compenvurb sys. 2020.101523

O'Kelly ME, Niedzielski MA (2009) Are long commute distances inefficient and disorderly? Environ Plann A: Econ Space 41(11):2741-3275

O'Kelly ME, Niedzielski MA, Gleeson J (2012) Spatial interaction models from irish commuting data: variations in trip length by occupation and gender. J Geogr Syst 14:357-387. https://doi. org/10.1007/s10109-011-0159-3

Owen A, Levinson DM (2015) Modeling the commute mode share of transit using continuous accessibility to jobs. Transp Res A Policy Pract 74:110-122. https://doi.org/10.1016/j.tra.2015.02.002

Poelman H, Dijkstra L (2015) Measuring access to public transport in European cities. Regional Working Paper.

Ramosa R, Cantilloa V, Arellanaa J, Sarmiento I (2017) From restricting the use of cars by license plate numbers to congestion charging: analysis for Medellin, Colombia. Transp Policy 60:119130. https://doi.org/10.1016/j.tranpol.2017.-09.012

Reyes M, Páez A, Morency C (2014) Walking accessibility to urban parks by children: a case study of Montreal. Land Urban Plann 125:38-47. https://doi.org/10.1016/j.landurbplan.2014.02.002

Ritsema van Eck J, Burghouwt G, Dijst M (2005) Lifestyles, spatial configurations and quality of life in daily travel: an explorative simulation study. J Transp Geogr 13:123-134. https://doi. org/10.1016/j.jtrangeo.2004.04.013

Rosik P, Pomianowski W, Komornicki T, Goliszek S, Szejgiec-Kolenda B, Duma P (2020) Regional dispersion of potential accessibility quotient at the intra-European and intranational level. Coreperiphery pattern, discontinuity belts and distance decay tornado effect. J Transp Geogr 102554. https://doi.org/10.1016/j.jtrangeo.2019.102554

Rosik P, Puławska-Obiedowska S, Goliszek S (2021) Public transport accessibility to upper secondary schools measured by potential quotient: The case of Kraków,. Moravian Geogr Reports 1 Forthcoming.

Rothfeld R, Straubinger A, Paul A, Antoniou C (2019) Analysis of European airports' access and egress travel times using Google Maps. Transp Policy 81:148-162. https://doi.org/10.1016/j. tranpol.2019.05.021

Salonen M, Toivonen T (2013) Modelling travel time in urban networks: comparable measures for private car and public transport. J Transp Geogr 31:143-153. https://doi.org/10.1016/j.jtran geo.2013.06.011

Schwartz B (2010) How does Google's predictive traffic maps work? Publishing PhysicksWeb. https:// www.seroundtable. com/archives/023155.html. Accessed 15 November 2018

Shearmur R (2006) Travel from home: an economic geography of commuting distances in Montreal. Urban Geogr 27(4):330-359. https://doi.org/10.2747/0272-3638.27.4.330

Shirgaokar M (2014) Employment centers and travel behavior: exploring the work commute of Mumbai's rapidly motorizing middle class. J Transp Geogr 41:249-258. https://doi.org/10.1016/j.jtran geo.2014.10.003

Stępniak M, Goliszek S (2017) Spatio-temporal variation of accessibility by public transport-the equity perspective. In: Ivan I, Singleton A, Horák J, Inspektor T (eds) The rise of big spatial data. Springer, Berlin, pp 241-261. https://doi.org/10.1007/978-3-319-45123-7_18 
Stępniak M, Pritchard JP, Geurs KT, Goliszek S (2019) The impact of temporal resolution on public transport accessibility measurement: review and case study in Poland. J Transp Geogr 75:8-24. https://doi.org/10.1016/j.jtrangeo.-2019.01.007

Toole JL, Colak S, Sturt B, Alexander LP, Evsukoff A, Gonzalez MC (2015) The path most travelled: travel demand estimation using big data resources. Transp Res Part C: Emerg Technolo 58:162177. https://doi.org/10.1016/j.trc.2015.04.022

Vallone A, Chasco C, Sánchez B (2020) Strategies to access web-enabled urban spatial data for socioeconomic research using R functions. J Geogr Syst 22:217-239. https://doi.org/10.1007/s1010 9-019-00309-y

Vickerman RW (1974) A demand model for leisure travel. Environ Plan A 6:65-77. https://doi. org/10.1068/a060065

Vickerman R, Spiekermann K, Wegener M (1999) Accessibility and economic development in Europe. Reg Stud 1(33):1-15. https://doi.org/10.1080/00343409950118878

Wang C-H, Chen N (2015) A GIS-based spatial statistical approach to modeling job accessibility by transportation mode: case study of Columbus, Ohio. J Transp Geogr 45:1-11. https://doi. org/10.1016/j.jtrangeo.2015.03.015

Wang F, Xu Y (2011) Estimating O-D matrix of travel time by Google Maps API: implementation, advantages and implications. Ann GIS 17:199-209. https://doi.org/10.1080/19475683.2011.625977

Wang L, Li L, Wu B, Bai Y (2013) Private Car switched to public transit by commuters, in Shanghai, China. Proc Soc and Beh Sci 96:1293-1303. https://doi.org/10.1016/j.sbspro.2013.08.147

Wessel N, Allen J, Farber S (2017) Constructing a routable retrospective transit timetable from a realtime vehicle location feed and GTFS. J Transp Geogr 62:92-97. https://doi.org/10.1016/j.jtran ge-o.2017.04.012

Wessel N, Widener M (2016) Discovering the space-time dimensions of schedule padding and delay from GTFS and real-time transit data. J Geogr Syst 19:93-107. https://doi.org/10.1007/s1010 9016-0244-8

Widener M, Minaker L, Farber S, Allen J, Vitali B, Coleman PC, Cook B (2017) How do changes in the daily food and transportation environments affect grocery store accessibility? Appl Geogr 83:46-62. https://doi.org/10.1016/j.apgeog.2017.03.018

Widener MJ, Farber S, Neutens T, Horner M (2015) Spatiotemporal accessibility to supermarkets using public transit: an interaction potential approach in Cincinnati, Ohio. J Transp Geogr 42:72-83. https ://doi.org/10.1016/j.jtrangeo.2014.11.004

Xia N, Cheng L, Chen S, Wei XY, Zong WW, Li MC (2018) Accessibility based on gravity-radiation model and Google Maps API: a case study in Australia. J Transp Geogr 72:178-190. https://doi. org/10.1016/j.jtrangeo.2018.09.009

Yin Z, Jin Z, Ying S, Li S, Liu Q (2020) A spatial data model for urban spatial-temporal accessibility analysis. J Geogr Syst 22:447-468. https://doi.org/10.1007/s10109-020-00330-6

Yongling Y, Guonan Z (2009) Empirical analysis of spatial mismatch of living-working: based on a field survey in downtown Beijing. Int J Urban Sci 13(1):1-17. https://doi.org/10.1080/12265 934.2009.9693643

Publisher's Note Springer Nature remains neutral with regard to jurisdictional claims in published maps and institutional affiliations. 